\title{
HÆMODYNAMIC STUDIES IN PATIENTS WITH ARTIFICIAL PACEMAKERS
}

\author{
BY \\ EDGAR SOWTON* \\ From the Cardiac Department, St. George's Hospital, London S.W.1 \\ Received November 26, 1963
}

The treatment of complete heart block by means of an artificial pacemaker is now well established, but there is still considerable uncertainty as to the best heart rate and the relative merits of fixed or variable rate units. The present study is based on 35 patients and the results are supported by clinical experience of a further 41 who have all been treated by artificial pacing for up to four years.

\section{SubJECTS AND MeThods}

The patients were attending a pacemaking clinic at St. George's Hospital. Treatment by artificial pacing was instituted only after the failure of a full medical régime, the indication for pacing in most cases being recurrent Stokes-Adams attacks. Pacing was initially by electrode catheter to the right ventricle in all cases, and Davies pacemakers $\dagger$ giving a $2 \mathrm{~m}$. sec. square wave biphasic pulse were used (Davies, 1962). Clinical details and results of treatment will be reported elsewhere.

Cardiac output was measured by an indicator-dilution method using Coomassie blue dye and a Cambridge Mark II recorder with earpiece oximeter, the results being expressed as relative outputs with the initial value as 100 per cent (Towers et al., 1961; Gabe, Tuckman, and Shillingford, 1962; Phinney et al., 1963). Preliminary studies showed that under constant conditions with patients at rest five measurements of relative cardiac ouput could be made with results that differed by 7 per cent or less. During the determination of output-time curves cardiac output measurements were made at two-minute intervals: during the determination of rate-output curves the output was measured four minutes after each alteration in pacemaker rate. Conversion of relative output to litres/min. was made by calibration of the first curve by means of control and end-tail blood samples: the absolute values are approximate.

Resting measurements were made when the patients were sitting with the trunk supported at about 45 degrees. Exercise studies were carried out on a bicycle ergometer (Gabe and Robinson, 1960), on which the power setting could be varied in steps of 5 Watts. Table I gives the approximate oxygen uptake (B. Robinson, 1963, personal communication) and equivalent activity of various settings on this apparatus.

TABLE I

Bicycle Ergometer: APproximate Oxygen Uptake

\begin{tabular}{r|l|c}
\hline Watts & \multicolumn{1}{|c|}{ Activity } & $\begin{array}{c}\text { O }_{2} \text { Uptake } \\
\text { (ml./min.) }\end{array}$ \\
\hline 30 & Walking at moderate pace & 900 \\
50 & Walking briskly & 1200 \\
80 & Running gently & 1500 \\
100 & Running moderately hard & 1800 \\
\hline
\end{tabular}

* Present Address: Institute of Cardiology, 35 Wimpole Street, London W.1.

† Obtainable from Devices Ltd., Welwyn Garden City, Herts. England. 

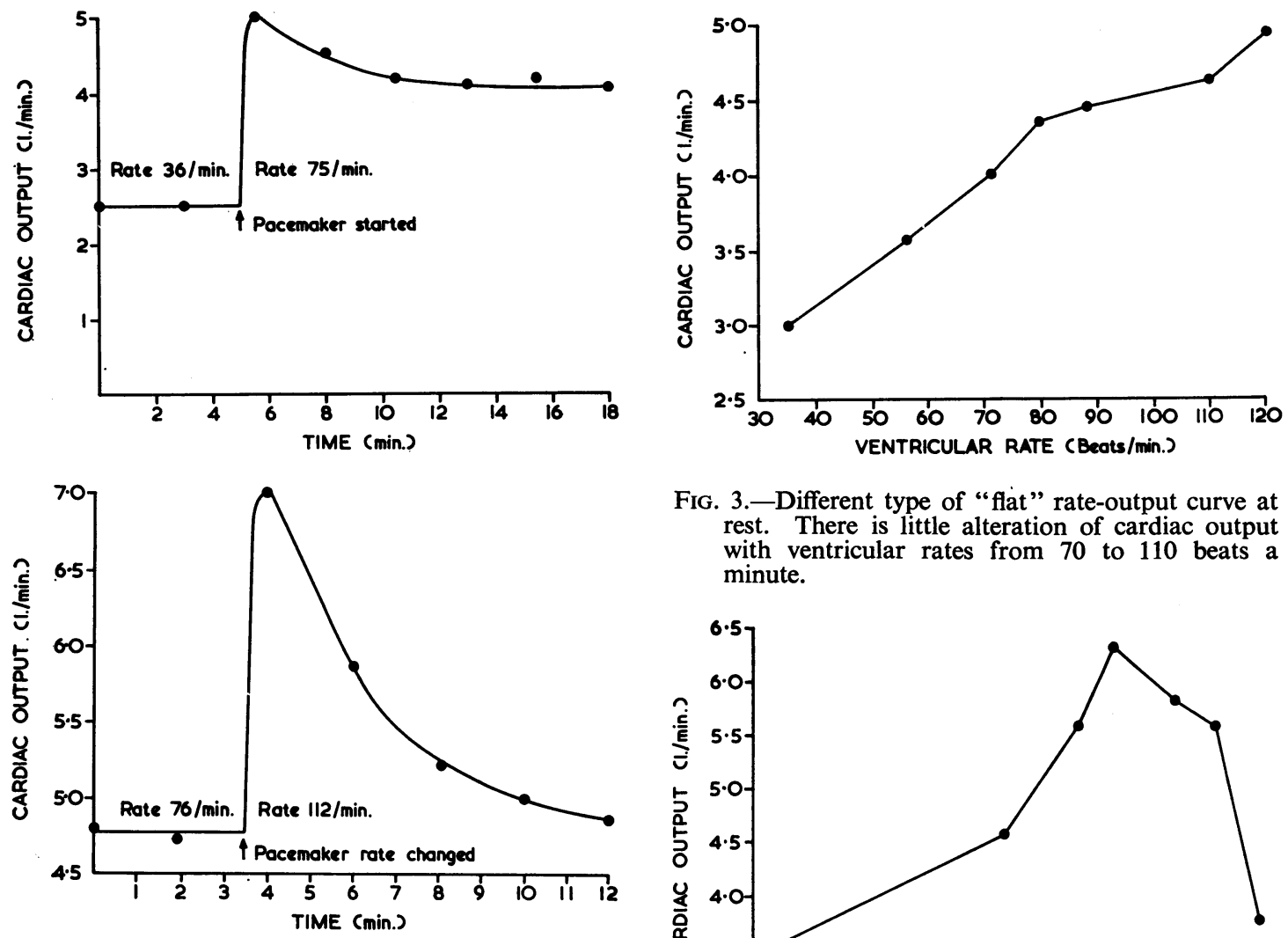

Fig. 1.-Upper: When the ventricular rate was suddenly increased from 36 to 75 beats a minute the cardiac output was initially doubled but adjusted to a new steady state over the next few minutes.

Lower: When the ventricular rate was increased from 76 to 122 beats a minute the cardiac output adjusted to the original level over the next few minutes, despite the persistence of the tachycardia.

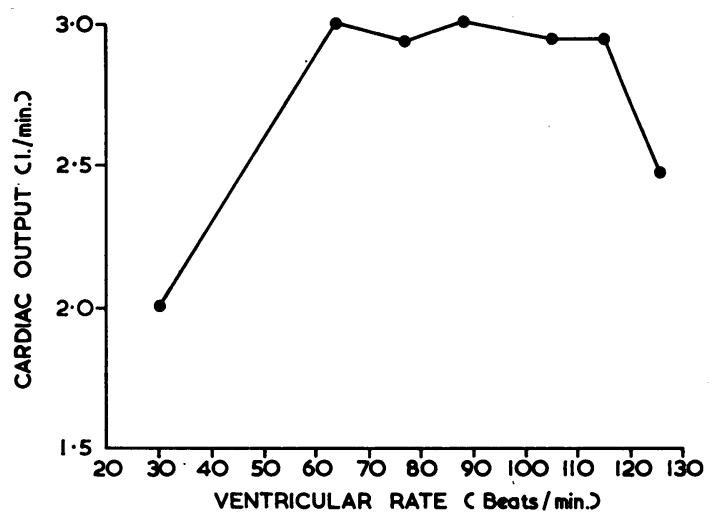

Fig. 2.- "Flat" type of rate-output curve at rest. The cardiac output is independent of ventricular rate over wide limits.

FIG. 3.-Different type of "flat" rate-output curve at rest. There is little alteration of cardiac output with ventricular rates from 70 to 110 beats a minute.

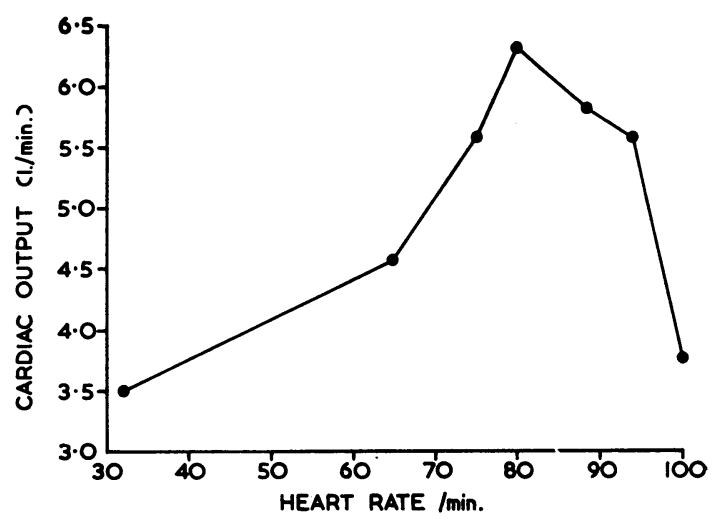

FIG. 4.- "Peaked" type of rate-output curve at rest. Cardiac output is critically dependent upon ventricular rate.

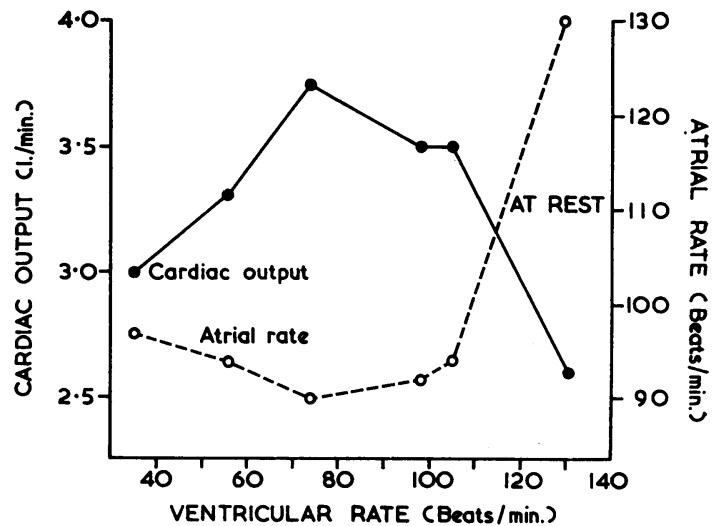

FIG. 5.-The atrial rate at rest was inversely related to the cardiac output: maximal output occurred at the pacemaker rate resulting in minimal atrial rate. 
Pressure traces and many of the electrocardiograms were taken with a Cambridge photographic recorder, while a Cambridge direct-writing electrocardiograph was used for the remainder. An oscilloscopic trace of the cardiogram was monitored continuously throughout all investigations.

\section{RESULTS}

Output-time Curves. If the ventricular rate was suddenly altered by means of the pacemaker, while the patient remained in the same resting state, serial measurements of cardiac output showed that changes in stroke volume occurred rapidly and that the output stabilized at a new steady state within a few minutes. If the patient was originally in a low output state from complete heart block the new steady state was reached with a larger cardiac output. If the patient was originally being paced at a satisfactory rate and the pacemaker setting was suddenly increased, the alterations in stroke volume resulted in the output returning to near its original level despite the increased ventricular rate. These changes are illustrated in Fig. 1, and similar results were found when the ventricular rate was suddenly reduced. Five patients were investigated in this way and in every case cardiac output proved to be almost independent of heart rate, provided enough time was available for compensating changes to take place before measurements were made. The time needed for this adjustment varied but was always between three and seven minutes.

Rate-output Curves. With the patient at rest cardiac output was measured at different ventricular rates in 28 patients, and two distinct types of rate-output curve were found. The first type of curve was relatively flat with output independent of rate over a wide range. Curves were classified as "flat" when the cardiac output did not vary by more than 15 per cent over a range of 30 beats a minute, and 14 patients $(50 \%)$ had curves in this category. Of these, $10(36 \%$ of total) showed a fall-off in output at the higher rates (Fig. 2$)$ and $4(14 \%)$ showed increasing outputs up to the maximum reached (Fig. 3). In all cases stroke volume varied inversely with ventricular rate over a wide range so that adjustments were in a direction tending to maintain a constant cardiac output.

The second type of rate-output curve was peaked, with the flow falling off sharply on either side of a critical ventricular rate (Fig. 4), and this type of curve was found in 14 patients $(50 \%)$. The distinction between "flat" and "peaked" curves was arbitrary and there were many examples of intermediate curves forming a gradation from completely flat curves to very peaked curves.

During the investigation of rate-output curves, electrocardiograms were taken while the outputs were being measured and atrial rates determined for each ventricular rate. In all cases the atrial rate altered with different pacemaker settings, slowing initially but becoming rapid at fast ventricular rates. In 20 of the 28 cases $(71 \%)$ there was a clear relation with the cardiac output, the minimum atrial rate corresponding to maximum output. These changes are illustrated in Fig. 5 . The relation depended upon the patient remaining quietly at rest throughout the entire investigation, and was most striking in the case of two patients who fell asleep; if the patients became excited, or even engaged in animated conversation, the atrial rate increased, presumably owing to alterations in sympathetic tone. Treatment with drugs also affected the atrial response, which could be abolished by atropine or chlorpromazine, although large doses were necessary.

Recordings of right atrial (RA) pressure and wedged pulmonary capillary (PC) pressure were made on 5 patients during the determination of resting rate-output curves. All these patients had "peaked" rate-output curves, and all showed similar responses (Fig. 6). As the ventricular rate increased, the RA pressures fell to a minimum, while the PC pressures remained steady in 4 patients and rose slightly in the fifth.

It is apparent that in many patients there was an optimal rate at which the cardiac output was maximal, the venous pressure lowest and the atrial rate minimal. It proved possible to identify this optimal rate in 18 of the 28 patients $(64 \%), 10$ patients with "flat" curves being excluded. The optimal rate was also identified in a further 6 patients from a study of the atrial changes and the results in these 24 patients are shown as a histogram in Fig. 7. Optimal rates were scattered over a 

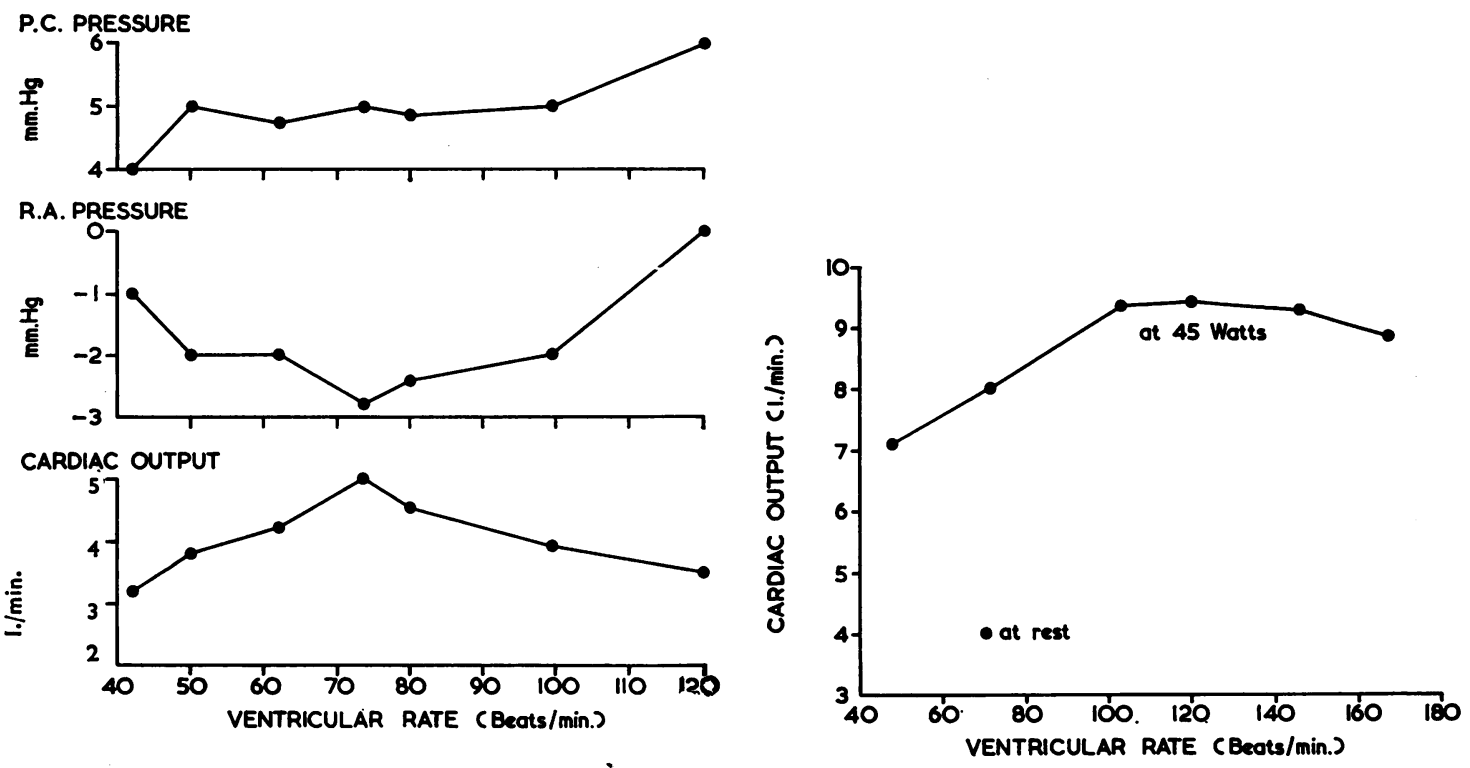

FIG. 6.-The R. A. pressure reaches a minimum at the ventricular rate corresponding to maximal cardiac output.

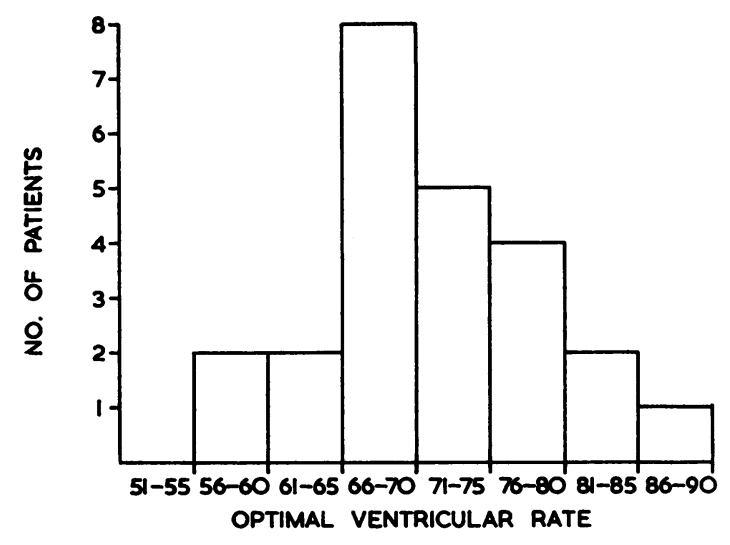

FIG. 7.-Histogram of optimal ventricular rates at rest.

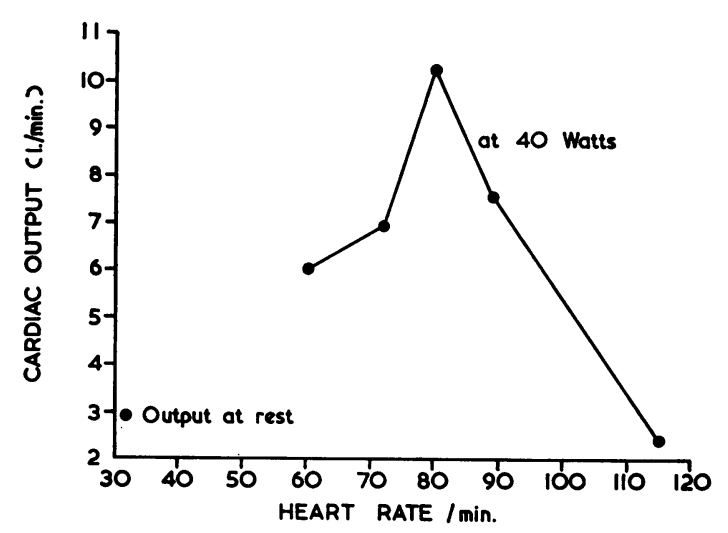

FIG. 8.-The two types of rate-ouput curve on exercise. Upper. "Flat": the cardiac output reached a plateau at about 100 beats a minute.

Lower. "Peaked": the cardiac output was critically dependent upon ventricular rate.

range of 56 to 90 beats a minute, with a mean of 71 beats a minute. Most patients fell in the 65-70 beats a minute range and the optimal rates were mainly concentrated in the normal sinus range. The mean value of cardiac output at rest before pacing was $2.91 . / \mathrm{min}$. (S.D. 0.8) and the mean value during pacing at the optimal rates was 4.41 ./min. (S.D. 0.6), an increase of 52 per cent.

Exercise Studies. Fifteen patients were also investigated on the bicycle ergometer, rate-output curves being obtained in 12 of them and maximum exercise tolerance being measured in 7 of these 12 and in 3 others.

During exercise rate-output curves were determined with a four-minute delay in the same way as at rest. Two types of curve were found and are illustrated in Fig. 8. Six patients with "flat" resting curves had "flat" exercise curves also, in which the cardiac output reached a plateau at about 100 beats a minute; further increase in pacemaker rate produced no appreciable alteration in flow 
TABLE II

Ventricular Rates on Exercise in Patients with

"Flat" RATE-OUTPUt CuRves

\begin{tabular}{c|c|c}
\hline $\begin{array}{c}\text { Patient } \\
\text { No. }\end{array}$ & $\begin{array}{c}\text { Rate at start of plateau } \\
\text { (beats/min.) }\end{array}$ & $\begin{array}{c}\text { Level of exercise } \\
\text { (Watts) }\end{array}$ \\
\hline 1 & 105 & 45 \\
2 & 100 & 20 \\
3 & 95 & 30 \\
4 & 110 & 30 \\
5 & 96 & 30 \\
6 & 90 & 40 \\
\hline
\end{tabular}

TABLE III

Optimal Rates at Rest and on Exercise in Patients With "Peaked" Rate-output Curves

\begin{tabular}{c|c|c|c}
\hline $\begin{array}{c}\text { Patient } \\
\text { No. }\end{array}$ & $\begin{array}{c}\text { Optimal rate } \\
\text { at rest } \\
\text { (beats/min.) }\end{array}$ & $\begin{array}{c}\text { Optimal rate } \\
\text { on exercise } \\
\text { (beats/min.) }\end{array}$ & $\begin{array}{c}\text { Level of } \\
\text { exercise } \\
\text { (Watts) }\end{array}$ \\
\hline 7 & 81 & 78 & 20 \\
8 & 70 & 75 & 20 \\
9 & 74 & 78 & 25 \\
10 & 79 & 79 & 40 \\
11 & 85 & 85 & 35 \\
12 & 68 & 76 & 30 \\
\hline
\end{tabular}

until a fall-off in output occurred at high rates. On the other hand six patients with "peaked" resting curves showed similar "peaked" curves on exercise. The ventricular rates at the start of the plateau in the patients with "flat" curves are given in Table II, and a comparison between optimal rates at rest and on effort in the patients with "peaked" curves is given in Table III. The rates quoted are those determined from the electrocardiograms taken during the investigation.

It is apparent from Tables II and III that patients with "flat" curves did not benefit from an increase in rate above about 100 beats a minute and patients with "peaked" curves had similar optimal rates on exercise and at rest. The exercise tolerances of 10 patients were measured on the bicycle ergometer to assess the effect of a fixed ventricular rate during exertion. Cardiac output and atrial rate were measured as before at increasing wattage settings until each patient's limit was reached. On exercise, both cardiac output and atrial rate increased in direct relation to power produced despite the fixed ventricular rate (Fig. 9 and 10). The changes in cardiac output and the wattages reached by these 10 patients are given in Table IV.

It is apparent that the fixed pacemaker rate did not prevent moderately high levels of activity being reached: changes in stroke volume enabled cardiac outputs to be raised from a mean of 4.0 $1 . / \mathrm{min}$. to a mean of $10 \cdot 21 . / \mathrm{min}$., at least for short periods.

In an attempt to determine some of the factors influencing the rate-output curves an analysis of their shapes in relation to clinical features of the patients was carried out in 21 patients for whom full details were available, including a good $6 \mathrm{ft}$. postero-anterior chest radiograph taken before pacing started, when cardiac failure was not present (Table V).

The criteria for classification of the rate-output curves have already been given: for the purpose of this analysis the diagnosis of myocardial disease depended on the presence of one or more of the following features. (1) Evidence of myocardial fibrosis at necropsy or operation. (2) Proven cardiac infarction in the past. (3) History of effort angina. (4) S-T depression of at least $1 \mathrm{~mm}$. in 


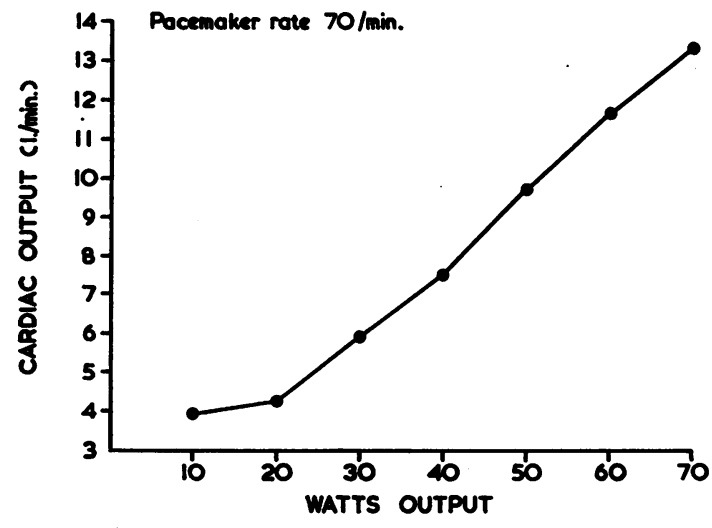

Fro. 9.-Cardiac output was directly related to power produced despite the fixed ventricular rate, and increased from 41 ./min. to 121 ./min. with exercise.

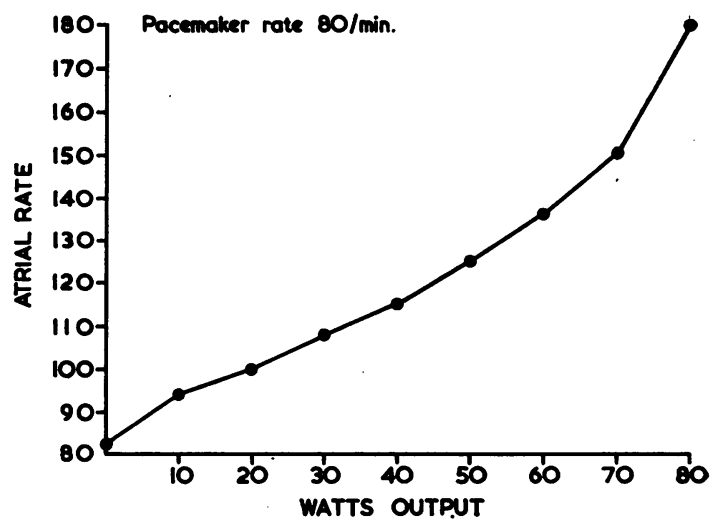

FIG. 10.-The atrial rate increased directly with power produced despite the fixed ventricular rate.

TABLE IV

Effect of a Fixed Ventricular Rate on Cardiac Output During Exercise

\begin{tabular}{c|c|c|c|c|l}
\hline \multirow{2}{*}{$\begin{array}{c}\text { Patient } \\
\text { No. }\end{array}$} & $\begin{array}{c}\text { Age } \\
\text { (years) }\end{array}$ & \multicolumn{2}{|c|}{ Cardiac output } & $\begin{array}{c}\text { Maximum } \\
\text { exercise level } \\
\text { (Watts) }\end{array}$ & $\begin{array}{c}\text { Type of rate } \\
\text { output curve }\end{array}$ \\
\cline { 2 - 4 } & $\begin{array}{c}\text { At rest } \\
\text { (1./min.) }\end{array}$ & $\begin{array}{c}\text { On effort } \\
\text { (1./min.) }\end{array}$ & & \\
\hline 1 & 54 & 4.5 & 13.5 & 70 & Flat \\
4 & 74 & 3.9 & 5.3 & 40 & Flat \\
5 & 52 & $4 \cdot 3$ & 10.0 & 60 & Flat \\
6 & 58 & 3.8 & 14.0 & 100 & Flat \\
7 & 66 & 3.8 & 6.0 & 40 & Peaked \\
10 & 39 & 3.0 & 8.5 & 60 & Peaked \\
12 & 76 & 3.0 & 8.5 & 50 & Peaked \\
13 & 67 & 3.5 & 9.2 & 60 & Flat \\
14 & 66 & 5.0 & 12.0 & 70 & Flat \\
15 & 60 & 5.0 & 14.0 & 80 & Flat \\
\hline
\end{tabular}

TABLE V

analysis of Rate-output Curves and Clinical Data in 21 Patients

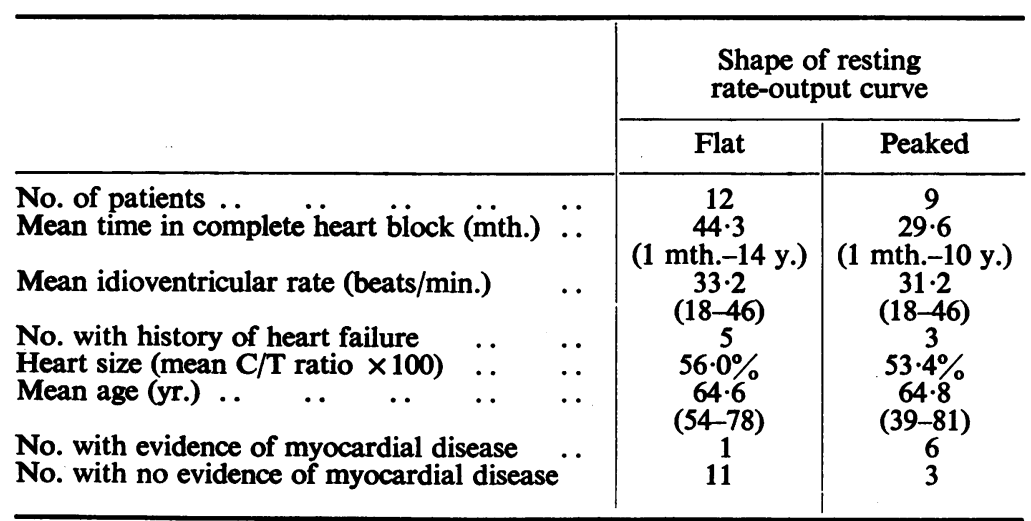

Figures in parentheses indicate ranges 
more than one lead of the cardiogram. (5) Left bundle-branch block pattern (LBBB) shown on the cardiogram at any time.

Dexter and Sowton (Sowton, 1964) have compared clinical and cardiographic findings with coronary angiograms after death in patients with complete heart block and concluded that patients with idioventricular beats of RBBB pattern often have excellent coronary arteries and almost normal cardiac muscle, while those with LBBB pattern are likely to have widespread ischæmic heart disease. The criteria adopted for the diagnosis of myocardial disease are likely to include patients with myocarditis or myopathy as well as those with ischæmic disease. The group of patients with no evidence of myocardial disease probably corresponds to the group diagnosed as "primary heart block" by Zoob and Shirley Smith (1963).

There was no correlation between the shape of the rate-output curve and time in heart block, idioventricular rate, history of heart failure, heart size or age, but there was a relation between evidence of myocardial disease and peaked curves; this correlation was statistically significant $(0.01$ $<\mathrm{p}<0.02)$.

\section{Discussion}

The output-time curves illustrated here show that under study conditions in these patients, control mechanisms adjusted stroke volume in a direction tending to maintain a constant cardiac output despite alterations in ventricular rate. It follows that in the determination of cardiac outputs at various rates the timing of the measurements was important; if a long period elapsed between the change in rate and the output measurement there was often little difference between the flows, while if cardiac output was measured immediately after the rate was changed large differences were found. In normal life short-term changes in cardiac output are constantly occurring, and it seems reasonable to relate the measurements to an adjustment time in which a relatively normal heart would reset the output to a new steady state. On the basis of the output-time curves obtained, a delay of 4 minutes was chosen between alterations of rate and measurement of cardiac output; the work of Berry et al. (1959) on atropine tachycardia in man suggests that completely normal hearts reset the output a little more rapidly than the hearts of those patients with Stokes-Adams disease. It is apparent that a patient with complete heart block but a relatively normal myocardium should be able to reset the cardiac output within the four-minute adjustment period and this should result in a flat-output curve. As this study has shown, there was a significant correlation between "flat" rate-output curves and absence of myocardial disease. Similar results were reported by Warner and Toronto (1960) who paced normal dogs' hearts at different rates and found that cardiac output was independent of ventricular rate over a wide range, both at rest and on exercise, while Bristow et al. (1963) also found that the stroke volume of paced dogs' hearts altered in a manner opposing the rate changes.

On the other hand several workers have reported that maximum resting cardiac outputs in patients with complete heart block were obtained at critical pacemaker rates (Müller and Bellet, 1961; Escher et al., 1961; Hudson, 1962; Bevegård, 1962), and though the very limited information available on the timing of measurements makes comparison difficult, it seems likely that these reports are equivalent to the finding of "peaked" rate-output curves in the present series.

The fall-off in flow at rapid rates is probably due to several factors; as the rate increases diastole shortens and ventricular filling becomes increasingly dependent upon atrial delivery which is largely absent in patients with complete heart block. Braunwald and Frahm (1961) have pointed out that the atrial contribution to ventricular filling is more important than usual in patients with abnormal hearts, and in the present series it was those patients with evidence of disease of the myocardium in whom the fall-off was most pronounced. This factor alone is not sufficient to explain the findings, since the proportion of atrial beats falling in a hæmodynamically useful interval rises from about 25 per cent at a ventricular rate of 55 beats a minute to about 50 per cent at 115 beats a minute (Sowton, 1964) and so the effect of atrial delivery increases as ventricular rate increases. 
It is likely that the most important additional factor is increased resistance to ventricular distension, related both to the hypertrophy following complete heart block and to the involvement of the myocardium by the ætiological agent. Brockman (1961) found that even normal dogs' hearts deteriorated in this way fairly rapidly after surgical induction of complete heart block, and Miller et al. (1962) felt that stiff ventricles were important in producing a fall-off in cardiac output at high rates in their dogs. This factor would account well for the increased fall-off in the group with myocardial disease in the present series. Possible other factors are the relative inefficiency of beats stimulated from the ventricle (Gilmore et al., 1963) and the development of atrio-ventricular valve regurgitation at high rates (Gilmore et al., 1963); the results at rest are compatible with the redistribution of blood from the central to the peripheral circulation suggested by Bevegård (1962).

The "correct" setting for a fixed-rate artificial pacemaker will be critical only in patients with "peaked" rate-output curves, and these patients are likely to have evidence of myocardial disease. In this group the optimal rates at rest and on exercise are similar, and it is sometimes possible to determine the optimal ventricular rate from the changes in atrial rate at different pacemaker settings, the final choice being that which gives the lowest atrial rate, as measured 4 minutes after the change in ventricular rate. This test is difficult to use routinely because the atrial rate is so sensitive to minor changes in sympathetic tone but it is usually possible to determine whether the rate-output curve will be peaked or flat; if the atrial rate-ventricular rate curve is fairly flat then the pacemaker setting is not critical. Patients with "flat" rate-output curves may benefit from an increase in rate on exercise up to a maximum of about 100 beats a minute, but this group have no evidence of myocardial disease and are those best able to compensate for a fixed rate by rapid alterations of stroke volume. A fixed rate pacemaker is acceptable in patients with both "peaked" and "flat" rateoutput curves, and this view is confirmed by the performance of these patients on the ergometer as well as by clinical experience. The present study indicates that a rate of $65-70$ beats a minute will be satisfactory for most patients, and many other workers report satisfactory clinical results with fixed rate units stimulating at about 70 beats a minute (Zoll et al., 1961; Johansson et al., 1963; Landegren and Biorck, 1963), although Chardack et al.'s group (1963) claim that a rather slower rate provides maximal coronary flow.

The disadvantages of external control of pacemakers are considerable (Siddons, 1963) and the possibility of an unsuitable choice of rate by the patient cannot be ignored. Elmquist et al. (1963) report that many patients found it difficult to decide which rate was correct and this would be expected from the "flat" rate-output curves found in the present investigation. The problems of rate adjustment are emphasized by a comparison of the report of Kantrowitz et al. (1962) with that of Glass, Shaw, and Smith (1963). Both groups have adopted a basic pacemaker rate of 60 beats a minute with a similar method of external control, but Kantrowitz et al. recommended that the rate be increased for the post-operative period, while Glass et al. recommend that the unit be slowed at this time. A hazard peculiar to the unit used by Kantrowitz et al. is the possibility of the patient increasing the rate until pacing suddenly ceases, a situation that is particularly likely to result in prolonged asystole.

The changes in atrial rate described in this paper can all be interpreted as the results of control mechanisms that would tend to adjust cardiac output to metabolic demand had the ventricle been able to follow the atrium. At rest, the metabolic demand is fairly constant, and the atrial responses to artificial alteration of ventricular rate were those tending to maintain a steady cardiac output: when the patient exercised the atrial rate increased, reflecting the normal tachycardia response to exercise. Changes in atrial rate similar to those reported here have also been noted in other centres (Bevegård, 1962).

Implantable pacemakers that produce synchronized atrial and ventricular contractions have recently been developed (Nathan et al., 1963), and hæmodynamic findings under these conditions show considerable improvement over simple ventricular pacing (Samet et al., 1963; Sowton, 1964). Until more experience of this type of unit is available it is suggested that the use of an implantable fixed-rate pacemaker is the most satisfactory method of long-term artificial pacing. 


\section{SummaRY AND CONCLUSIONS}

Thirty-five patients with complete heart block have been investigated. The conclusions are supported by clinical experience in a further 41 patients.

Cardiac outputs measured four minutes after changes in rate were nearly independent of ventricular rate in 14 patients without evidence of myocardial disease, but were critically dependent upon rate in 14 patients with myocardial disease, both at rest and on exercise.

There was an optimal ventricular rate at rest in most patients. At this rate cardiac output was maximal, venous pressure lowest, and atrial rate minimal. The optimal rates ranged from 55 to 90 beats a minute with a mean of 71 beats. The optimal rates on exercise for patients with myocardial disease were very close to the optimal rates at rest. In all patients a fixed ventricular rate was acceptable if correctly chosen, and enabled moderate activity to be carried out.

Artificial pacing increased the mean cardiac ouput in 28 patients from 2.91 . $/ \mathrm{min}$. to $4.41 . / \mathrm{min}$. Exercise with a fixed ventricular rate increased the mean cardiac output in 10 patients from $4.01 . / \mathrm{min}$. to $10 \cdot 21 . / \mathrm{min}$. Of these 10 patients, 4 increased their output to $121 . / \mathrm{min}$. or more.

I am grateful to Dr. Aubrey Leatham for his encouragement and criticism and to Mr. J. G. Davies for technical assistance. This paper is based upon material included in a thesis accepted for an M.D. degree of the University of Cambridge.

\section{REFERENCES}

Berry, J. N., Thompson, H. K., Jr., Miller, D. E., and McIntosh, H. D. (1959). Changes in cardiac output, stroke volume, and central venous pressure induced by atropine in man. Amer. Heart J., 58, 204.

Bevegård, S. (1962). Observations on the effect of varying ventricular rate on the circulation at rest and during exercise in two patients with an artificial pacemaker. Acta med. scand., 172, 615.

Braunwald, E., and Frahm, C. J. (1961). Studies on Starling's law of the heart. IV. Observations on the hemodynamic functions of the left atrium in man. Circulation, 24, 633.

Bristow, J. D., Ferguson, R. E., Mintz, F., and Rapaport, E. (1963). The influence of heart rate on left ventricular volume in dogs. J. clin. Invest., 42, 649.

Brockman, S. K. (1961). Cardiodynamics in complete heart block. Circulation, 24, 893.

Chardack, W. M., Gage, A. A., Schimert, G., Thomson, N. B., Sanford, C. E., and Greatbatch, W. (1963). Two years' clinical experience with the implantable pacemaker for complete heart block. Dis. Chest, 43, 225.

Davies, J. G. (1962). Artificial cardiac pacemakers for the long-term treatment of heart block. J. Brit. Instn. Radio Engrs., 24, 453.

Elmquist, R., Landegren, J., Pettersson, S. O., Senning, Å., and William-Olsson, G. (1963). Artificial pacemaker for treatment of Adams-Stokes syndrome and slow heart rate. Amer. Heart J., 65, 731.

Escher, D. J. W., Schwedel, J. B., Eisenberg, R., Gitsios, C., Perna, N., and Jamshidi, A. (1961). Cardiovascular dynamic responses to artificial pacing of patients in heart block. Circulation, 24, 928.

Gabe, I., and Robinson, B. (1960). The cardiac output on exertion in normal and abnormal subjects. In Proceedings of the British Cardiac Society. Brit. Heart J., 22, 304.

—, Tuckman, J., and Shillingford, J. P. (1962). 'Determination of relative changes in cardiac output from noncalibrated earpiece dye-dilution curves.,Circulat. Res., 11, 405.

Gilmore, J. P., Sarnoff, S. J., Mitchell, J. H., and Linden, R. J. (1963). Synchronicity of ventricular contraction: observations comparing hæmodynamic effects of atrial and ventricular pacing. Brit. Heart J., $25,299$.

Glass, H., Shaw, G., and Smith, G. (1963). An implantable cardiac pacemaker allowing rate control. Lancet, 1, 684.

Hudson, W. A. (1962). Hæmodynamic effects of artificial cardiac pacemaking in patients with complete heart block. In Proceedings of the Thoracic Society. Thorax, 17, 180.

Johansson, B. W., Karnell, J., Malm, A., Sievers, J., and Swedberg, J. (1963). Electrocardiographic studies in patients with an artificial pacemaker. Brit. Heart J., 25, 514.

Kantrowitz, A., Cohen, R., Raillard, H., Schmidt, J., and Feldman, D. S. (1962). The treatment of complete heart block with an implanted, controllable pacemaker. Surg. Gynec. Obstet., 115, 415.

Landegren, J., and Biorck, G. (1963). The clinical assessment and treatment of complete heart block and AdamsStokes attacks. Medicine (Baltimore), 42, 171.

Miller, D. E., Gleason, W. K., Whalen, R. E., Morris, J. J., Jr., and McIntosh, H. D. (1962). Effect of ventricular rate on the cardiac output in the dog with chronic heart block. Circulat. Res., 10, 658.

Müller, O. F., and Bellet, S. (1961). Treatment of intractable heart failure in the presence of complete atrioventricular heart block by the use of the internal cardiac pacemaker. New Engl. J. Med., 265, 768.

Nathan, D. A., Center, S., Wu, C., and Keller, W. (1963). An implantable synchronous pacemaker for the long-term correction of complete heart block. Amer. J. Cardiol., 11, 362.

Phinney, A. O., Jr., Clason, W. P. C., Stoughton, P. V., and McLean, C. E. (1963). Measurement of cardiac output using the photoelectric earpiece: a comparison with simultaneous Fick measurements. Circulat. Res., 13, 80.

Samet, P., Jacobs, W., Bernstein, W. H., and Shane, R. (1963). Hemodynamic sequelae of idioventricular pacemaking in complete heart block. Amer. J. Cardiol., 11, 594. 
Siddons, A. H. M. (1963). Long-term artificial cardiac pacing: experience in adults with heart block. Ann. roy. Coll. Surg. Engl., 32, 22.

Sowton, G. E. (1964). Artificial cardiac pacemaking with particular reference to cardiac physiology. M.D. Thesis, University of Cambridge.

Towers, M., Wagner, G., Polis, O., and McDonald, L. (1961). A comparison of simultaneous earpiece and cuvette dye-dilution curves. In Proceedings of the British Cardiac Society. Brit. Heart J., 23, 461.

Warner, H. R., and Toronto, A. F. (1960). Regulation of cardiac output through stroke volume. Circulat. Res., $8,549$.

Zoll, P. M., Frank, H. A., Zarsky, L. R. N., Linenthal, A. J., and Belgard, A. H. (1961). Long-term electric stimulation of the heart for Stokes-Adams disease. Ann. Surg., 154, 330.

Zoob, M. and Shirley Smith, K. (1963). The ætiology of complete heart-block. Brit. med. J., 2, 1149. 